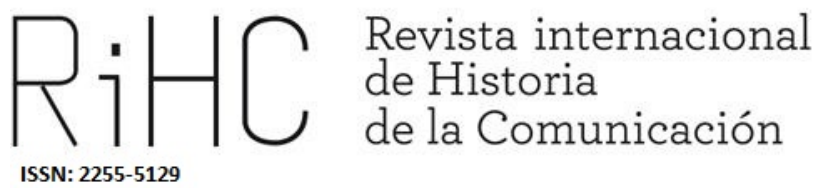

\title{
LA PRENSA ESPAÑOLA ANTE LA MARCHA SOBRE ROMA: ENTRE EL ENTUSIASMO Y LA HOSTILIDAD HACIA EL FASCISMO
}

The Spanish Press before the March on Rome: Between Enthusiasm and Hostility towards Fascism

DOI: http://dx.doi.org/10.12795/RiHC.2019.i13.09

Recibido: 09/10/2019

Aceptado: 06/12/2019

Publicado: $15 / 15 / 2019$

Ricardo Zugasti Azagra

Universidad de Zaragoza, España

rzugasti@unizar.es

ORCID (D) 0000-0002-8558-9605 
Resumen: el objetivo esencial de este artículo es analizar el tratamiento periodístico otorgado por la prensa diaria española a la Marcha sobre Roma y a la conquista del poder por el fascismo en Italia. Los diarios seleccionados son una muestra representativa de las distintas tendencias de la prensa de difusión nacional de aquel momento: ABC, El Debate, El Sol, La Libertad y El Socialista. De manera más concreta, el trabajo busca, en primer lugar, dibujar la imagen que sobre este primer fascismo triunfante proyectó la prensa; contribuir, en segundo lugar, a la caracterización ideológica de los diarios analizados; y conocer, por último, el ambiente político de la época plasmado en la prensa.

Palabras clave: Marcha sobre Roma, fascismo, prensa, España, Italia

\begin{abstract}
The main objective of this article is to analyze the journalistic treatment given by the Spanish daily press to the March on Rome and to the conquest of power by fascism in Italy. The selected newspapers are a representative sample of the different trends of the national press of that time: ABC, El Debate, El Sol, La Libertad and El Socialista. More specifically, the work seeks, in the first place, to draw the image that the press projected on this first triumphant fascism; contribute, secondly, to the ideological characterization of the analyzed newspapers; and to know, finally, the political environment of the time portrayed in the press.
\end{abstract}

Keywords: March on Rome, fascism, press, Spain, Italy

\title{
Introducción y metodología
}

Benito Mussolini y el Partido Nacional Fascista (PNF) conquistaron el poder en Italia con la llamada Marcha sobre Roma del 27 al 29 de octubre de 1922. Este éxito del movimiento fascista supuso una crucial novedad en el panorama político europeo del siglo $\mathrm{XX}$, y en dicha experiencia se inspiraron otros movimientos y regímenes surgidos en el continente durante el periodo de entreguerras. El fascismo italiano se convirtió, también en España, en un modelo, en "el ejemplo por antonomasia", para una derecha radicalizada en un clima nacional que consideraba agotado el vigente sistema liberal parlamentario (Ruiz Carnicer, 2015: 361). Cuando Mussolini se hizo con el gobierno, el régimen de la Restauración, vigente desde 1875, entraba en su último año. El 13 de septiembre de 1923, el golpe de Estado del general Primo de Rivera daba comienzo a una dictadura en España que, sin asimilarse plenamente al modelo italiano, lo consideraba un ineludible polo de influencia.

El primer contacto que el público español tuvo con el éxito del movimiento fascista italiano se estableció en las páginas de la prensa, que se llenaron con información y comentarios acerca de la Marcha sobre Roma y del acceso al poder del PNF en Italia. Los periódicos españoles lo consideraron el acontecimiento internacional del 
momento y la cobertura fue, por lo general, amplia y constante. De aquí deriva el propósito esencial de este trabajo: analizar el tratamiento periodístico otorgado a la Marcha sobre Roma por la prensa diaria española de dimensión nacional. Se trata, en definitiva, de esbozar qué imagen sobre este primer fascismo triunfante proyectaron algunas de las principales cabeceras de prensa sobre sus lectores. Los resultados permitirán asimismo contribuir a la caracterización ideológica de los diarios analizados a partir de su posicionamiento frente a los acontecimientos de Italia. Además, los distintos periodistas y articulistas, muchos de ellos vinculados con la política y la literatura, plasmaron en sus textos el espíritu de la época en la que el fascismo emergió como un referente frente a un sistema liberal percibido por muchos como agotado. Conocer esos retazos del ambiente político del momento plasmados en la prensa tiene interés para una mejor comprensión del humus donde empezó a germinar el fascismo.

Para alcanzar estos objetivos, se analizaron cinco diarios editados en Madrid y representativos de las principales tendencias ideológicas de la prensa española de aquel momento ${ }^{1} . A B C$ y $E l$ Debate se encuadraban en la prensa derechista, si bien con la diferencia de que el segundo era un periódico confesional católico y el primero se definía como liberal conservador y monárquico. Por otro lado, El Sol y La Libertad eran exponentes del liberalismo progresista, elitista uno y más popular el otro. El Socialista representaba la prensa obrera marxista, alejada de la vocación empresarial del resto de rotativos. Todos, a excepción del órgano periodístico del PSOE, se contaban entre los diarios más vendidos del país.

De cada uno de estos periódicos se revisaron exhaustivamente los ejemplares publicados entre el 21 de octubre y el 15 de noviembre de 1922, ambos días incluidos ${ }^{2}$. Se abarcaban de esta manera no sólo la Marcha sobre Roma y la formación del nuevo gobierno encabezado por Mussolini, sino también quince días adicionales con el fin de dar tiempo a que se plasmaran las primeras reacciones y valoraciones tras la toma del poder por el fascismo. La muestra quedó constituida por los editoriales, los artículos

\footnotetext{
${ }^{1}$ Se planteó incluir el diario barcelonés La Vanguardia, pero únicamente publicó informaciones de agencia y dos artículos de opinión: el primero fue redactado por el director del periódico y ofreció una visión del fascismo como reacción antiliberal, que equiparó a la protagonizada por Lenin, y de la que criticó su brutalidad y violencia ("Gaziel", 1 de noviembre de 1922: 14); el segundo, firmado por José María Salaverría (11 de noviembre de 1922: 10), fue de similar contenido al publicado por este autor en $A B C$ el 15 de noviembre de 1922 y comentado más adelante en este trabajo. Se accedió a ellos en la hemeroteca digital del periódico (https://www.lavanguardia.com/hemeroteca). Dada esta escasa cobertura, se optó por centrar el análisis en la prensa editada en Madrid y dotar así de mayor homogeneidad a la selección de fuentes primarias.

${ }^{2}$ Los ejemplares se localizaron en las colecciones digitalizadas de los periódicos disponibles online. El Debate y La Libertad, en la Biblioteca Virtual de Prensa Histórica (http://prensahistorica.mcu.es/es/inicio/inicio.do); El Sol, en la Hemeroteca Digital de la Biblioteca Nacional (http://www.bne.es/es/Catalogos/HemerotecaDigital/); $A B C$, en su propia hemeroteca online (http://hemeroteca.abc.es/); y El Socialista, en el Archivo de la Fundación Pablo Iglesias (http://archivo.fpabloiglesias.es/index.php).
} 
de opinión y las crónicas de corresponsales propios de cada periódico, que constituyen las fuentes primarias del trabajo. No se consideraron para el estudio las piezas informativas acerca de la Marcha sobre Roma procedentes de la agencia Fabra, de la que se nutrían todos los diarios, pues homogeneizaron la cobertura y, por lo tanto, no permitían conocer las diferencias discursivas en torno al objeto de estudio. La metodología empleada fue el análisis de contenido cualitativo, pues permite, a diferencia del cuantitativo basado en datos estadísticos, captar con mayor eficacia tanto los significados, los matices y los distintos énfasis de los textos, como mostrar las argumentaciones con sus connotaciones (Altheide, 1996).

Algunos trabajos previos han abordado la representación del fascismo italiano en la prensa española. Peloille (2005) analiza artículos periodísticos y libros sobre el fascismo italiano que se publicaron en España durante la dictadura de Primo de Rivera, aunque también incluye en su estudio los meses que precedieron el golpe del 13 de septiembre. De la misma autora son tres trabajos de menor entidad. El primero se centra en cómo se situó La Veu de Catalunya, diario catalanista editado en Barcelona, frente a la Marcha sobre Roma (Peloille, 2004); el segundo muestra la postura de la prensa liberal madrileña ante el fascismo entre 1922 y 1925 (Peloille, 2003); y el tercero ofrece un censo de todos los artículos de opinión sobre la Italia fascista publicados en seis diarios españoles entre 1922 y 1929 (Peloille, 2009). Pellegrini (2009), por su parte, estudia la Italia fascista en la prensa española del franquismo, entre 1940 y 1945. Por último, Gutiérrez esboza una aproximación al discurso católico sobre el fascismo en España y en Venezuela durante el periodo de entreguerras empleando como fuente El Debate (2010). No obstante, el trabajo que aquí se presenta aborda por primera vez una investigación centrada exclusivamente en la Marcha sobre Roma y en la llegada al poder del fascismo, y basada en un análisis hemerográfico exhaustivo de una pluralidad de cabeceras relevantes y representativas de la prensa española de la época.

\section{El fenómeno del fascismo y la Marcha sobre Roma como hito y referente}

El fascismo como tal nació tras la Primera Guerra Mundial, pero es posible localizar algunos de sus motivos y rasgos en movimientos políticos radicales, tanto de derechas como de izquierdas, de carácter nacionalista o marxista revolucionario, tal y como expone Gentile:

El mito de la voluntad de poder, la aversión hacia el igualitarismo y el humanitarismo; el desprecio por el parlamentarismo; la exaltación de las 
minorías activas; la concepción de la política como actividad para organizar y plasmar la conciencia de las masas; el culto a la juventud como nueva aristocracia dirigente; la apología de la violencia, de la acción directa, de la guerra y de la revolución. (2002: 24).

No obstante, la entonces llamada Gran Guerra, con los conflictos y desórdenes de diversa índole que provocó -económicos, sociales, políticos, culturales y morales-, fue la generadora de las condiciones para que el fascismo naciera y se desarrollara. Entre estas condiciones destaca la percepción general de cansancio o de agotamiento de la democracia liberal y parlamentaria, un marco político identificado con el siglo XIX que era visto como superado también por sectores amplios de las clases medias ubicados ideológicamente en la derecha radical y en el naciente fascismo: "Se dejaba atrás el viejo liberalismo parlamentario, convertido para estos con sus formalismos en obstáculo para hacer posible un nuevo renacimiento de la nación, la reafirmación de una identidad que se dice a punto de perderse" (Ruiz Carnicer, 2015: 346).

Puede considerarse el fascismo como una especie de revolución de las clases medias orientada a la conquista del poder, con un marcado carácter antiliberal, como hemos destacado, pero también antimarxista, con un alto componente reaccionario "contra los intentos de la nueva revolución, la de inspiración bolchevique" (Peloille, 2005: 33). No obstante, reducir el fascismo a una mera reacción de la clase burguesa frente a la amenaza revolucionaria marxista impide percibir la especificidad del fascismo como una "variante del modernismo" que busca adaptarse a la nueva sociedad de masas (Griffin, 2010: 21), una forma peculiar de modernidad que, como destaca Ruiz Carnicer, explica su "capacidad de atracción inicial" (2015: 347). Se trataba, en definitiva, de un movimiento inserto "en los conflictos y en las tensiones de la moderna sociedad de masas y en la violenta aceleración del proceso de movilización social y de modernización producido en la sociedad europea de la Primera Guerra Mundial" (Gentile, 2002: 63).

Este anclaje del fascismo en la modernidad, en el que el nuevo valor de la juventud como categoría política y su concepción activista de la vida no estuvieron al margen, reforzó una dicotomía "entre lo nuevo y lo viejo; entre la continuidad de un liberalismo aparentemente exhausto y las opciones hijas de la Gran Guerra" como el comunismo y el fascismo (Ruiz Carnicer, 2015: 345).

Mucho se ha escrito sobre el fenómeno del fascismo y no parece ser un asunto cerrado: siguen debatiéndose cuestiones como su propia naturaleza o su significado en la historia contemporánea. Partiendo de la experiencia italiana, y recogiendo muchos de los rasgos expuestos hasta aquí, Gentile propone una definición:

El fascismo es un fenómeno político moderno, nacionalista y revolucionario, antiliberal y antimarxista, organizado en un partido milicia, con una concepción 
totalitaria de la política y del Estado, con una ideología activista y antiteórica, con fundamento mítico, viril y antihedonista, sacralizada como religión laica que afirma la primacía absoluta de la nación a la que entiende como una comunidad orgánica étnicamente homogénea y jerárquicamente organizada en un Estado corporativo con una vocación belicista a favor de una política de grandeza, de poder y de conquista encaminada a la creación de un nuevo orden y de una nueva civilización. (2002: 19) ${ }^{3}$.

El fascismo alcanzó verdadera visibilidad mundial gracias a la conquista del poder en Italia con la Marcha sobre Roma y, a partir de ese momento, se convirtió en un modelo para otros movimientos europeos nacionalistas antiliberales. No es la finalidad de este trabajo exponer detalladamente la historia del fascismo italiano o los pormenores de la Marcha sobre Roma, si bien conviene plasmar algunas ideas que permitan contextualizar el análisis hemerográfico, que mostraremos más adelante.

El fascismo nació mediante el impulso de Benito Mussolini, un exdirigente del Partido Socialista que fue expulsado de este por su postura intervencionista en la guerra. En 1919 lanzó un llamamiento a los veteranos de la contienda para movilizarse al margen de las estructuras de los partidos tradicionales, lo que conformó los fasci di combattimento ${ }^{4}$.

Durante el conocido como "bienio rojo" (1919-1920), ejemplificado en la ocupación socialista de las fábricas, se desencadenó una serie de conflictos sociales sin precedentes que dieron la impresión de colocar a Italia al borde de una guerra civil. La burguesía asistía temerosa a un inminente trasunto de revolución bolchevique en Italia, mientras percibía que el Estado liberal parecía impotente frente al desafío. Ahí encontró su hueco la violencia escuadrista de los fascistas, algo consustancial a este movimiento desde su creación. Haciendo permanente uso de ella, se colocó al frente "de la reacción antisocialista", perfilándose como defensor de la burguesía y de las clases medias, lo que le transformó en un movimiento de masas que se arrogó "el monopolio del patriotismo" (Gentile, 2015: 47).

Fue habitual que, especialmente desde posiciones liberales, se considerara el fascismo un fenómeno contingente, producto de la postguerra, y que se apaciguaría con su entrada en las instituciones. De ahí, por ejemplo, que Giovanni Giolitti, Presidente del Consejo de Ministros, les diera cabida en las listas electorales que patrocinó de cara a las elecciones de 1921. Fue una errónea percepción que se repetirá, agravada, durante el desarrollo de la Marcha sobre Roma, como veremos.

\footnotetext{
${ }^{3}$ Desde una perspectiva más genérica, Payne define el fascismo de manera básicamente coincidente: "Una forma de ultranacionalismo revolucionario que se basa en una filosofía primariamente vitalista, que se estructura en la movilización de masas, el elitismo extremado y el Führerprinzip, que da un valor positivo a la violencia y tiende a considerar normales la guerra y las virtudes militares" (1995: 24).

${ }^{4}$ El programa político de los fasci, publicado en 1919, está en Hernández Sandoica (1992: 98-99).
} 
Durante el verano de 1921 el fascismo atravesó una grave crisis derivada de la divergencia de visiones acerca de qué vertiente debería tener mayor peso: la escuadrista o, como postulaba Mussolini, la política. El peligro se alejó manteniendo ambas vías activas: el movimiento se convertiría en un partido político -el Partido Nacional Fascista-, con Mussolini como Duce; pero mantendría la rama paramilitar en activo.

Un año después el fascismo decide tomar el poder, asumiendo que se encontraba ante un "ahora o nunca" histórico. En aquel momento, "con más de doscientos mil inscritos, una milicia armada, asociaciones femeninas y juveniles, apoyado por sindicatos que contaban con casi medio millón de afiliados, el PNF era la organización política más poderosa del país" (Gentile, 2002: 33). El método empleado puede calificarse como una insurrección con negociaciones. La insurrección propiamente dicha, la Marcha sobre Roma, fue concebida como medida de presión y de chantaje para llegar al poder. Esto se combinó con negociaciones que Mussolini y el secretario general del PNF, Michele Bianchi, mantuvieron por separado con los principales dirigentes liberales, a quienes hicieron creer que cada uno de ellos era el candidato preferido por los fascistas. Les proponían elecciones anticipadas en poco tiempo y presencia fascista en el nuevo gobierno. Una vez más se hizo notar la confianza de la vieja clase política dirigente en la capacidad del régimen liberal para asimilar a los fascistas y salvar así la situación. No obstante, como destaca Gentile, los políticos liberales no estaban dispuestos a emplear la violencia contra el chantaje armado fascista:

Todos coincidían en rechazar el uso de la fuerza legal para reprimir la fuerza ilegal del PNF, temiendo que la represión desencadenase una guerra civil entre el Estado y el fascismo, con la cual se beneficiarían tan sólo los socialistas y los comunistas. (2015: 198).

Del 27 al 29 de octubre de 1922 miles de fascistas armados procedentes de diversos lugares de Italia marcharon hacia Roma. Cuando Luigi Facta, el Primer Ministro en funciones, le presentó el día 28 al rey el texto del decreto que proclamaba el estado de sitio, Víctor Manuel III rechazó firmarlo. De nuevo emergía la preferencia por evitar la guerra civil y dejar abierta la puerta a una solución legalista que pudiera integrar el fascismo en la monarquía liberal. "Los viejos liberales confiaban en que las cosas seguirían como antes", asegura expresivamente Ferguson al respecto (2007: 308). Ese mismo día, Mussolini rechazó formar parte de un gabinete presidido por Antonio Salandra. Al día siguiente, el rey encargó a Mussolini formar gobierno.

Una fuerza política nueva, organizada paramilitarmente, se había hecho con el gobierno de un Estado liberal. "Nada similar había sucedido vez alguna", subraya Gentile (2015: 16). Este éxito, con todo lo que suponía, convirtió el fascismo italiano en un referente para la derecha radical en España. Desde la Marcha sobre Roma estos sectores políticos contaban, según Mainer, con "un activo modelo [...] en el que 
mirarse con envidia" (2013: 21). Además, era un modelo cercano a España por razones históricas, religiosas y culturales; ambas eran "potencias de mediana categoría" con similares problemas interiores (Peloille, 2005: 26). Pese a que un fascismo español propiamente dicho y organizado no cuajará hasta los años treinta, sí existía en España un sustrato común, una cultura política compartida entre diversos sectores de esa "derecha intransigente" de la que habla Preston (1096), que hizo que personas de

diferentes tendencias y trayectorias vitales hicieran una lectura "expectante $\mathrm{y}$ esperanzada del fascismo mussoliniano" (Ruiz Carnicer, 2015: 349). A ello contribuyó, sin lugar a dudas, la influencia sobre estos sectores políticos de una prensa derechista que fue el primer canal de entrada en España de una visión positiva del nuevo régimen italiano (Rodríguez Jiménez, 1997; Maurel, 2005).

\section{Marco legal de la prensa y caracterización de los diarios analizados}

La situación jurídica de la prensa española en 1922 estaba definida en la Ley de Policía de Imprenta de 1883. Fue una norma promovida por los liberales fusionistas, y eliminó el tratamiento específico de los delitos de prensa e imprenta y, como consecuencia, los tribunales debían basarse en las leyes ordinarias. Se consagró de esta manera un sistema no preventivo, sino represivo, que concedía considerables márgenes de maniobra para la prensa. La vigencia de la ley permitió "la existencia de un notable pluralismo periodístico, que abarcaba desde periódicos integristas y carlistas hasta los declaradamente socialistas y marxistas" (Barrera, 2004a: 129). Pese al establecimiento sólido de ese principio de libertad, también debe tenerse en cuenta que no era infrecuente la suspensión de las garantías constitucionales y el establecimiento de la censura militar "en cuanto sucedían acontecimientos graves" (Desvois, 1977: 8), un recurso que no se aplicó en el periodo estudiado. Este era el marco jurídico general en el que se desenvolvieron los cinco periódicos analizados al tratar la Marcha sobre Roma. A continuación se ofrece una breve semblanza de cada uno de ellos, centrada en su perfil ideológico y en los lectores a quienes se dirigían.

$A B C$, fundado por el empresario Torcuato Luca de Tena, salió a la calle en 1903 diariamente desde 1905- y su perfil político puede sintetizarse en la tríada "monarquismo, españolismo y conservadurismo" (Sánchez Aranda y Barrera, 1992: 282). Era un diario liberal conservador, defensor del orden y del principio de autoridad, que apoyó el regeneracionismo encarnado en Maura. Se declaraba defensor de los principios católicos, pero no era una cabecera confesional como El Debate. Se convirtió en el periódico preferido de las clases conservadoras acomodadas, pues consiguió 
"llenar un hueco en el panorama de la gran prensa madrileña, dominado [...] por diarios situados a la izquierda" (Seoane y Sáiz, 1996: 84).

El Debate, el otro gran diario conservador de difusión nacional, nació en 1910, y desde 1912 fue propiedad en exclusiva de la Asociación Católica Nacional de Propagandistas. Se trataba de un rotativo confesional, impulsado y dirigido por Ángel Herrera, que se convirtió en "el más importante periódico del catolicismo español y uno de los más influyentes del periodismo español de estos años" (Seoane y Sáiz, 1996: 123). En el terreno político, propugnó la creación de un nuevo partido de derechas que sustituyera el conservador, y antes del golpe de Estado de Primo de Rivera defendió una dictadura civil que prescindiese del parlamento y que preservase el orden social. Según Guasch Borrat, "hubiese deseado que Maura se convirtiese en ese dictador" (1986: 434). Se caracterizaba El Debate por ser un periódico elitista, serio y denso, que sintonizó sobre todo con "las clases medias de la España profunda" (Seoane y Sáiz, 2007: 168).

Un diario elitista fue asimismo El Sol, considerado por Desvois como "el periódico de mayor prestigio que existió en España antes de la Guerra Civil" (2010: 166). Nació en 1917, por iniciativa de Nicolás María de Urgoiti, empresario del sector papelero, y el prominente intelectual José Ortega y Gasset. De tendencia "reformista liberal", fue, junto a La Libertad, representante de la nueva izquierda burguesa que cristalizó en la década de 1920 (Barrera, 2004b: 286). La flor y nata de la intelectualidad de la época colaboró en el diario, que reclutaba sus lectores entre "los intelectuales, profesionales progresistas y la burguesía dinámica y reformista de las provincias más desarrolladas" (Seoane y Sáiz, 2007: 129). El Sol propugnaba "cambio, reforma, renovación, evolución, sin romper la legalidad y mucho menos el orden social vigente" (Seoane y Sáiz, 1996: 245).

La Libertad nació en 1919, fruto de la disidencia de varios redactores de El Liberal. Ideológicamente se ubicó en "un liberalismo reformista burgués" de izquierda similar al de El Sol (Sánchez Aranda y Barrera, 1992: 246), aunque con un enfoque y estilo alejados del elitismo intelectual. De hecho, se afianzó gracias al dinero proporcionado por Santiago Alba, quien necesitaba un periódico que defendiera las posturas de su nuevo partido Izquierda Liberal. Explotando una de las claves de su éxito, la sintonía con el público popular madrileño, se convirtió en uno de los principales periódicos informativos madrileños. Su público pertenecía mayoritariamente a la pequeña burguesía o a la clase obrera. En palabras de Seoane y Sáiz, "La Libertad representa en estos primeros tiempos la postura más radical dentro del liberalismo democrático, abierto a las izquierdas, aun a las extremas, pero muy especialmente al socialismo" (1996: 263).

El Socialista, fundado en 1886 por Pablo Iglesias, fue desde 1890 el órgano oficial del PSOE, por lo que se encuadra en el modelo de prensa de partido. Era notoria "la 
seriedad extrema con que el diario obrero mantenía y hacía honor a sus postulados y principios" (Moral Sandoval, 1987: 528). Siempre presentó, por lo tanto, un "carácter doctrinal más que informativo", aunque a partir de su conversión en diario en 1913, proporcionaba más información de actualidad (Sánchez Aranda y Barrera, 1992: 253254). El hecho de que los obreros que compraban periódicos se inclinaran por diarios populares de alta circulación como La Libertad en el caso de Madrid, explica en parte su exigua tirada. No obstante, el "entusiasmo proselitista" de los militantes socialistas extendía la influencia del periódico a través, por ejemplo, de "lecturas colectivas" (Seoane y Sáiz, 2007: 137 y 170).

\section{La Marcha sobre Roma en la prensa española}

\section{1 $A B C$ : una tribuna para difundir el fascismo}

En $A B C$ cobraron especial relevancia las crónicas de Rafael Sánchez Mazas, su corresponsal en Roma, publicadas bajo el título genérico de "ABC en Roma" o "ABC en Italia". En ellas, Sánchez Mazas manifestaba una admiración entusiasta hacia el fascismo. La primera tras el triunfo de la Marcha sobre Roma, fechada por el autor el 28 de octubre, no dejaba lugar a dudas:

Los partidos a caballo han ganado siempre, ganan siempre y siempre ganarán. Por andar a caballo -que es como decir a paso gentil y a paso heroico- un puñado de españoles ganó el Imperio de los incas y el Imperio de los aztecas. Los pobres indios les creyeron hombres maravillosos. Pues este mismo infalible experimento acaban de repetir los fascistas con el espeso y tupido socialismo italiano de 1922. La historia es como un juego de naipes: Cambia la ocasión, pero las suertes son siempre las mismas. Esta noche de sábado, del 28 de Octubre, Caballo y Rey han cantado 'las cuarenta' a todo un naipe obscuro de demócratas, de socialistoides, de politicantes, de memos pseudo-contemporáneos, de crédulos, de antipatriotas y de toda la banda averiada que Italia ha padecido cincuenta años. (3 de noviembre 1922: 3).

La Marcha sobre Roma supuso, pues, "una revolución a caballo, una revolución a paso gentil, una revolución aristocrática del pueblo -no de las masas-, incruenta y elegante" que consiguió interrumpir "cincuenta años de mito democrático, algunos lustros de abyección socialista y una infame intentona final de crimen bolchevique". Muestra 
asimismo Sánchez Mazas una aceptación y minimización de la violencia ejercida por los fascistas: "Se ha apaleado, como a un personaje de comedia, a algún socialista malhumorado" (3 de noviembre 1922: 3).

El asalto fascista al poder dio lugar a algunos artículos de opinión que $A B C$ ubicó en la privilegiada página tres del diario, al igual que hizo con algunas crónicas de su corresponsal en Roma. El común denominador era una valoración positiva del fascismo, si bien menos entusiasta que la transmitida por las crónicas de Sánchez Mazas. José María Salaverría, un periodista y escritor que colaboraba en diversas publicaciones conservadoras, analizó "la probabilidad de que en España pudiera repetirse el fenómeno del fascio". A diferencia de España,

Italia ha soportado la profunda y larga conmoción de la guerra [...]. Desde la derrota casi inminente al triunfo casi repentino e inesperado, y después de la bancarrota financiera a la amenaza de un comunismo violento y antinacional.

La herencia de la neutralidad española en la Gran Guerra era a juicio del autor el impedimento para que el fascismo triunfara:

La guerra ha dejado a España, junto con algún dinero de más, una serie de vicios, una costumbre de gasto, un desenfreno del juego y una mayor soberbia de los nacionalismos regionales, puesto que las mayores ganancias de la guerra se quedaron en los dos focos del nacionalismo separatista: Barcelona y Bilbao.

Eran precisamente estos nacionalismos periféricos los que impedían el resurgimiento de España:

Frente a la acción unificadora y reintegradora de Francia, Italia y Grecia, España se entretiene con pequeños problemas y comete la sandez de subdividir su gran nacionalismo -el nacionalismo español que nos orientara hacia América, hacia el mundo- en esas múltiples pequeñas patrias, en esas grotescas y trágicas mascaradas del nacionalismo, del separatismo provincial, grietas por donde se escapa la mejor fuerza de España. (7 de noviembre de 1922: 4) 5 .

Un día después fue Álvaro Alcalá Galiano quien firmó una loa al fascismo italiano. Para el publicista aristócrata, la Marcha sobre Roma era un triunfo de "la reacción" capitaneada por el "contrarrevolucionario" Mussolini, quien iba a hacer "desde las alturas del poder, esa 'revolución desde arriba' con que soñaba el Sr. Maura”" . No era, sin embargo, obra "de un solo partido derechista", sino "una reacción nacional en la que tienen su representación todas las clases sociales". ¿Contra qué se reaccionaba?

\footnotetext{
${ }^{5}$ Mainer (2013) y Ruiz Carnicer (2015) destacan el papel que tuvieron los nacionalismos periféricos en la reactivación de un nacionalismo español que fue relevante en la gestación del fascismo.

${ }^{6}$ Resulta interesante la alusión a Maura, ya que "el maurismo es una movilización política de la derecha en donde se contienen algunos elementos que utilizarán los fascistas" (Ruiz Carnicer, 2015: 358).
} 
Italia, agotada por la guerra y desangrada por el mal estado de su hacienda, la rivalidad de sus políticos, su desgastada máquina parlamentaria, las huelgas perpetuas y las explosiones revolucionarias del comunismo rojo, ha roto sus cadenas.

Había también en Alcalá Galiano una justificación de la violencia ejercida por el fascismo, entendida fundamentalmente como una sana lucha contra el marxismo revolucionario:

Antes de asaltar el Poder ha sabido dar la batalla, en las calles, a todos los que eran un obstáculo a este renacimiento nacional. Ha luchado contra los gobiernos débiles, contra los socialistas recalcitrantes y contra los obreros comunistas que aspiraban a convertir Italia en una sucursal de los Soviets rusos. Ha asaltado las redacciones de aquellos periódicos que en lugar de defender el sagrado interés nacional defendían intereses mezquinos, y ha quemado, en muchísimas ciudades, esas Casas del Pueblo, que no sólo explotaban a la clase obrera, sino que aspiraban a implantar la 'dictadura del proletariado'.

Tras cargar contra el parlamento y "su absoluta esterilidad", miraba hacia España:

¿Tendrán imitadores en otros países? ¿Podrá el fascismo traspasar las fronteras y agitar a otras naciones más apáticas? Yo siempre he soñado con una especia de fascismo para España, con ese dictador que gobernara sin Cortes [...], que tuviese el ánimo y las fuerzas para barrerlo todo, de arriba abajo. (8 de noviembre de 1922: 3).

El mismo colaborador de $A B C$ publicó otro artículo días después, significativamente titulado "Parlamentarismo estéril y democracia anticuada", en el que se afanaba en mostrar que el liberalismo y el régimen parlamentario estaban heridos de muerte en Europa. Alcalá Galiano terminaba el texto fijando su mirada en Italia y, por comparación, en España:

La explosión del fascismo en Italia, esa irresistible ola reaccionaria que ha elevado a Mussolini hasta las gradas del Trono y del Poder, les advierte [a los políticos liberales] la posibilidad de que la reacción puede estallar también en otros países. Y Mussolini es la negación del parlamentarismo y de las teorías democráticas. Simboliza la acción contra la verbosidad. ¿No resulta cómico, después de haber leído la rapidez con que ha formado su Ministerio, leer las idas y venidas de nuestros prohombres en torno a una probable crisis, que será como tantas otras? El posible advenimiento al Poder de nuestros conocidos parlamentarios liberales me hace el mismo efecto de esos platos que devolvemos a la cocina por incomibles y que nos vuelven a servir recalentados. (14 de noviembre de 1922: 4). 
También a la crisis del "democratismo ochocentista" dedicó José María Salaverría un nuevo artículo que centró en la influencia intelectual de Nietzsche en esta "decadencia del liberalismo parlamentario en Europa". Para el colaborador de $A B C$, la Marcha sobre Roma fue "un caso representativo de las tendencias modernas" y Mussolini, "el verdadero representante, ágil y meridional, de esta pasmosa transformación que están sufriendo las ideas europeas en este dramático y tembloroso principio del siglo XX" (15 de noviembre de 1922: 3$)^{7}$.

Rafael Sánchez Mazas volvió a firmar una crónica centrada en la Marcha sobre Roma en la que hizo gala de nuevo de su entusiasmada adhesión a esa "revolución festiva" aplaudida por "todas las clases sociales", que suponía

...un cambio esencial en el más íntimo régimen del Estado, en el concepto de jerarquía y de eficacia, en la exaltación sin reservas del poder real, en la primacía de los deberes patrios frente a las ambigua arcadias de derechos, en la íntegra conciencia de una Patria existente y definida frente a la miserable ilusión de un romanticismo internacional seudo-humanitario y económico.

El resto de la crónica proyectó la imagen de una toma incruenta del poder y buscó atenuar la violencia fascista. Sirva como ejemplo el último párrafo:

Las fascistas han sido viriles, divertidos y generosos. No han tomado represalias de tantos atentados miserable y cobardemente perpetrados por la vileza roja de todos los países. Han puesto en ridículo, han emplumado como a malas mujeres, han obligado a beber aceite ricino a unos cuantos apóstoles de la Humanidad, y eso ha bastado. Lo más, lo más que han hecho es dar una azotaina en los barrios extremos y mandar a la cama a alguna partida de conscientes y subversivos. (Sánchez Mazas, 15 de noviembre de 1922: 5).

\subsection{El Debate: condicionado por la relación entre el fascismo y la Iglesia}

El corresponsal en Roma del diario católico, Ettore O. Daffina, ofreció una semblanza de Mussolini y una breve caracterización del fascismo nada más hacerse este con el poder. Al líder le definió como "un agitador" apologeta de la violencia, que procedía del ala extremista del socialismo y que giró hacia el nacionalismo motivado por la guerra. En cuanto al origen del fascismo, lo explicó así:

Termina la guerra. Los socialistas dominan la nación durante dos años. Los primeros grupos de fascistas surgen en 1919 en Milán, en Trieste y en la región

\footnotetext{
${ }^{7}$ Gentile sostiene que en el origen del fascismo hay influencia de la filosofía de Nietzsche, como en todas "las ideologías fundadas en la negación del Ser o de la Razón" (2002: 98).
} 
de Emilia. Poco a poco van agrupándose; a partir de la ocupación de las fábricas por los obreros, el fascismo adquiere importancia. Giolitti, que los necesita para luchar contra el socialismo, les presta el apoyo gubernamental; los patrones contribuyen con dinero al sostenimiento y a la acción de los 'fasci'. Ni el uno ni los otros podían prever el desarrollo formidable que tomaría el movimiento.

No era la de Daffina una crónica halagadora hacia el fascismo. Le achacó "falta de equilibrio" y de excederse en el uso de su fuerza:

La fuerza que debía servir para dominar el ataque socialista se empleó después para todo: desde obligar a una casa de automóviles -la casa Bugatti, francesa- a correr en el circuito de Milán (¿cómo iba a quedar satisfecho el patriotismo fascista si no era derrotada una marca francesa?) hasta invadir una propiedad, cuyo dueño se resiste a emplear unos obreros sin trabajo. (30 de octubre de 1922: 1$)^{8}$.

Otra crónica del mismo corresponsal, fechada en Roma el 26 de octubre, antes de que se le concediera el Gobierno a Mussolini, incide en la explicación y desarrollo del fascismo. En ella, cobra importancia la actitud maximalista de los socialistas a partir de las elecciones de noviembre de 1919:

Los socialistas no se limitaron a una oposición en condiciones ordinarias, sino que, simpatizando muchos de sus afiliados con el bolchevismo ruso, creyeron que había llegado el momento de provocar la subversión social y de conquistar por la violencia sus objetivos. Inicióse entonces la táctica extremista del socialismo, que impidió al parlamento funcionar con normalidad, formuló pretensiones excesivas a pretexto de reforma social, promovió la ocupación de tierras por grupos de campesinos y llegó hasta la ocupación de las fábricas por los obreros.

En el mismo texto, Daffina consideró que la aproximación del fascismo al poder le conducía "hacia las vías de legalidad" y alejaba "el peligro de una insurrección contra el Estado". "Una vez que los fascistas participen en el Gobierno, habrán de ajustar su organización a la estructura nacional y emplearla en asegurar el orden", valoró el periodista. En cuanto a la relación entre fascistas y el católico Partido Popular Italiano, un aspecto importante dado el carácter confesional del periódico, Daffina pronosticaba fácil entendimiento:

La colaboración entre unos y otros es tanto más probable cuanto que los fascistas hacen hincapié en cuestiones políticas y sociales de carácter nacional, pero no combaten ninguna tendencia religiosa. El mismo Mussolini, en un

\footnotetext{
${ }^{8}$ Durante la primera mitad de 1922, el confesional Partido Popular Italiano también fue objeto de la violencia e intimidación fascistas (Gentile, 2015).
} 
memorable discurso pronunciado ante el Parlamento, reconoció la alta fuerza moral del Pontificado, no sólo como poder eminentemente conservador, sino como elemento que ha favorecido el esplendor y el decoro de Italia. (31 de octubre de 1922: 3).

El corresponsal del diario católico prestaba, lógicamente, especial atención a todo aquello que emanase da la Santa Sede para orientar su postura hacia el fascismo. Estas informaciones se nutrían fundamentalmente de lo que publicaba el diario oficioso del Vaticano, L'Osservatore Romano. Tomó de este rotativo un llamamiento del Papa a favor de la pacificación de Italia emitido antes de la toma del poder por Mussolini (Daffina, 1 de noviembre de 1922a: 1) y, tras este, una noticia de la satisfacción papal por el mantenimiento del orden y que los sucesos no degeneraran "en conflicto sangriento y fratricida" (Daffina, 1 de noviembre de 1922b: 1 ).

La satisfacción por la moderación y el pragmatismo que imprimirían en el fascismo sus nuevas responsabilidades de gobierno latía asimismo en un editorial de El Debate titulado expresivamente "Una cosa es predicar...". Destacó que "en veinticuatro horas de Poder" hubo "tres rectificaciones fundamentales" respecto a su programa en la oposición: no iba a convocar elecciones inmediatamente, no iba a modificar la ley electoral y se habían realizado gestos tranquilizadores hacia Yugoeslavia, en torno estos al conflicto por la cuestión adriática (2 de noviembre de 1922: 1).

La misma idea de la capacidad moderadora de la asunción del gobierno estaba presente en un artículo de opinión del profesor de economía en Deusto Ramón de Olascoaga, centrado en la política europea: "El fascismo es, en ese sentido, por su pronunciada tendencia imperialista, un peligro; pero la responsabilidad del Poder quizá lo atenúe" (4 de noviembre de 1922: 1).

La moderación mostrada tras asumir responsabilidades de gobierno y la inclusión de dos ministros populares en el ejecutivo, así como la atenuación de su carácter anticlerical hicieron que El Debate viera con mejores ojos a este fascismo aparentemente más civilizado. Así, en un editorial usó el caso italiano para ejemplificar el giro a la derecha que estaba experimentando Europa y que el diario anhelaba para España:

¡Mientras tanto, en España, cuando la política en Europa se orienta resueltamente hacia la derecha, los jefes liberales tienen la audacia de pedir el Poder e invocar el genial pensamiento del marqués de Alhucemas de que esta es la hora de las izquierdas! (4 de noviembre de 1922: 1).

\footnotetext{
${ }^{9}$ En los círculos vaticanos las opiniones sobre el fascismo oscilaban durante estos días entre el optimismo y el pesimismo. Para la Iglesia Católica, lo importante era que se preservase el orden y se mitigaran las acciones violentas (Gentile, 2015).
} 
Dos crónicas de Daffina son reveladoras de esta nueva imagen más aceptable del fascismo que proyectó El Debate. La primera enumeraba una serie de medidas de Mussolini que suponían atemperar los excesos producidos los días anteriores: devolver de edificios y periódicos socialistas ocupados, reintegrar los ayuntamientos a sus funciones ordinarias, restaurar el derecho de libre circulación, o la orden de detener a los agresores del diputado comunista Belloni (Daffina, 10 de noviembre de 1922: 2). En la segunda se mostraba la "óptima impresión" que había causado entre los católicos un editorial de II Popolo d'Italia, órgano de expresión del PNF, en el que se alababa el "profundo sentimiento religioso de muchos fascistas" y afirmaba que "la jerarquía eclesiástica" debía "ser respetada como todas las mayores jerarquías de la nación" (Daffina, 13 de noviembre de 1922: 3).

\subsection{El Sol: heterogeneidad en la opinión}

El diario inspirado por Ortega y Gasset publicó un editorial el 28 de octubre; de carácter descriptivo, narraba los sucesos acaecidos en los últimos días y daba por segura la concesión de dos carteras a los fascistas en el nuevo gabinete. Destacó el giro que el fascismo había dado desde el republicanismo hasta la reciente aceptación de la Monarquía. Era algo que -apuntaba el artículo- iba a suponer un acatamiento de la legalidad por el fascismo y, por lo tanto, serviría para moderar sus excesos:

No puede menos de sorprender con nuestras costumbres el caso de estas fuerzas, que entran a servir en la Monarquía por la violencia, por la amenaza. Sin embargo, la participación de las nuevas fuerzas con dos ministros en un Gobierno heterogéneo, como aquí decimos, en mezcla con los viejos políticos italianos, parece marcar el principio de la adaptación de los fascistas.

El texto transmitía una imagen poco optimista hacia el futuro del fascismo, pues iba "a ser eliminado de la lucha por absorción" en la Monarquía, institución que se disponía así "a vacunarse contra el fascismo inyectándose fascismo en su sangre" (28 de octubre de 1922: 5).

Un nuevo editorial vio la luz una vez que Mussolini se convirtió en presidente del consejo de ministros. Tras dejar entrever que el programa del fascismo era impreciso y ambiguo, el artículo miró hacia España. Según El Sol, el efecto que el triunfo del fascismo provocó en algunos sectores de la derecha era "curioso": "Hay quien se ve ya asaltando ministerios y oficinas [...]. Derechistas hay que ya tienen pensado su Mussolini para España". Por otro lado, los izquierdistas lo atribuían -continuaba el periódico- "a una especie de oscurecimiento de las conciencias", como hacían "con todos los fenómenos de reacción surgidos en Europa después de la guerra". Cargó el periódico buena parte de la responsabilidad en la radicalización de la izquierda: "La 
formidable reacción fascista no parece ser más que la réplica a una exageración contraria" (31 de octubre de 1922: 5).

El mismo día que el anterior editorial se publicó la primera crónica enviada desde Italia por José Pla, un nuevo colaborador de EI Sol, a quien se le encargó un estudio detenido del movimiento fascista. Haciendo gala de una mirada escéptica hacia el fascismo, habitual en sus crónicas, el periodista catalán recién llegado a Italia describió que este país "está como congestionado de fascismo, y lo que resta es incertidumbre". Estableció un paralelismo entre fascismo y comunismo, con la justificación de la violencia como principal nexo:

Un ciudadano pacífico, amante de la legalidad, educado en el régimen de relativa libertad burguesa, tiene sus apuros para distinguir el orden futuro que promete el fascismo del orden futuro que prometía el comunismo en 1919-20. Es poco humano, es contrario a las ideas del hombre sensual medio de un país, creer en los métodos violentos $y$, sobre todo, creer en una política de medios violentos, cuando, como ahora, la política y los políticos producen en todas partes tanto horror. (Pla, 31 de octubre de 1922: 5).

La siguiente crónica de Pla estaba fechada el 27 de octubre y describía el ambiente callejero que la movilización fascista había generado en Florencia. Terminaba comparando el fascismo con una enfermedad juvenil pasajera:

Sea cual sea la solución a la crisis, se resuelva en el Parlamento, o se realice un golpe de Estado y se vaya a un Ministerio sin contar con la mayoría, el caso es que Italia ha llegado al punto álgido de su crisis de postguerra. Agotadas la experiencia roja y la blanca, estas dos escarlatinas de la juventud de Italia, el país entrará en la normalidad (2 de noviembre de 1922: 5).

El liberal Eduardo Gómez de Baquero, crítico literario y colaborador en distintas publicaciones, dedicó al triunfo del fascismo un artículo muy crítico hacia este movimiento por su carácter antihumanista. Rechazó su violencia, sus "homicidios de veras" más allá de su apariencia teatral, afirmó el principio de que "la civilización es coexistencia, cooperación y por consiguiente tolerancia", y denunció "la indigencia de la ideología del fascismo", un "sistema esencialmente oportunista que no es de principios sino de práctica". Concluía comparando a Europa con un enfermo todavía bajo los efectos narcotizantes de la guerra; de ahí podía colegirse que el fascismo era algo transitorio:

Le dieron a ella [Europa] altas dosis de nacionalismo, de autoritarismo, de culto a la violencia. Se la descivilizó para que peleara hasta la muerte, y está muy reciente la anestesia de su humanismo para que podamos tomar sus náuseas y estremecimientos como signos normales de una nueva edad. (4 de noviembre de 1922: 5). 
El artículo de Gómez de Baquero suscitó la reacción expresa de Ramiro de Maeztu, también colaborador de El Sol, quien desde posiciones antiliberales esbozó las características de un supuesto y deseable fascismo ideal. Este asumiría la violencia "sin fuerza no hay hecho político"- y en España podrían abrazarlo "los sucesores de los viejos progresistas y todas nuestras clases medias, acompañadas de los obreros desengañados del ideario marxista":

No sé cómo será el fascismo italiano. No me gusta su nacionalismo, porque veo en el nacionalismo la localización y el empequeñecimiento de la Divinidad. Pero me satisface en cuanto significa ruptura del pacifismo e indiferentismo liberales. $Y$ estoy seguro de que el siglo XX no podrá enamorarse de un sistema de gobierno que lo mismo ampara el trabajo que la ociosidad, el pensamiento que la modorra, el valor que la cobardía. El ideal está en hacer obligatorios los bienes que el liberalismo individualista se contentaba con permitir: la cultura, la veracidad, el amor, la fuerza, la castidad, el trabajo, la sobriedad, la economía, la riqueza, el pensamiento, la cortesía, la elegancia y el valor. (7 de noviembre de 1922: 1).

El periodista y político socialista Luis Araquistáin firmó la más nítida crítica contra el fascismo en las páginas de El Sol. Afirmó que, como concepto general, era un movimiento político "contrarrevolucionario": recibió de la guerra "su hábito de la violencia" y lo aplicó "en defensa de los principios tradicionales de orden y patria" contra los que juzgaba "como agentes o partidarios de la revolución rusa". En relación con esto, consideró que el nuevo régimen iba a "parecerse al actual régimen ruso más que a ningún otro sistema europeo", pues el lenguaje de Mussolini no se diferenciaba esencialmente del de Lenin cuando hablaba "de la democracia y del parlamentarismo". Consideró asimismo que en las acciones de ciertas "bandas terroristas" que actuaban en España contra los marxistas estaba latente, al igual que en el fascismo, "la crisis del régimen parlamentario español"10. Por último, calibró atinadamente lo que suponían la Marcha sobre Roma y sus consecuencias:

Nominalmente, el fascismo italiano alcanza el Poder por procedimientos constitucionales, puesto que es el Rey quien le ofrece el Gobierno; pero ese acto del Monarca de Italia, que revela un fino intento de conservación, apenas puede encubrir, con la ficción de su constitucionalismo, la realidad a la cual ha tenido que rendirse, o sea, que el fascismo ha sido una revolución victoriosa, y que el Poder logrado por la fuerza, fuera de las combinaciones parlamentarias, es una forma de dictadura, que hará tabla rasa del Parlamento. (Araquistáin, 5 de noviembre de 1922: 1).

\footnotetext{
${ }^{10}$ Ruiz Carnicer (2015) explica la importancia de estos movimientos de tipo somatenista en la movilización de una derecha radicalizada que verá en el fascismo un modelo.
} 
Pla dedicó una de sus crónicas a esbozar un perfil de Mussolini. Le retrató como un exsocialista radical predicador de "un socialismo al rojo vivo" quien, con el estallido de la guerra europea, se convirtió "en intervencionista, militarista y patriota". Así resumió el periodista la configuración del fascismo:

Mussolini, con los descontentos de la paz, creó el fascismo. La política de los socialistas durante la guerra, perfectamente anfibia, y su política de la postguerra de mezquindad para con los mutilados y enfermos de las trincheras, el decreto de Nitti indultando a los desertores, el fracaso de la ocupación de las fábricas, dieron un primer impulso fuerte al fascismo. Este impulso decayó cuando Mussolini orientó el naciente partido hacia el republicanismo; pero pronto hizo marcha atrás, y los desengaños internacionales y la desocupación pusieron el resto. Hoy, el fascismo es un partido imponente. (4 de noviembre de 1922: 1).

El cronista de El Sol viajó en tren con los fascistas que regresaban de Roma y mantuvo una breve entrevista con uno de los cabos de una escuadra compuesta por obreros del campo, de la que deriva una cierta identificación entre socialismo y fascismo:

-A qué cree usted que se debe el rápido crecimiento del fascismo?

-Según mi opinión, a muchas causas. La primera, porque los desertores de la guerra fueron indultados, de manera que nosotros, que hemos hecho la guerra, tenemos hoy los mismos derechos que ellos. Luego, porque habiéndose apoderado el fascismo de los Sindicatos agrícolas de nuestra provincia, quien no es fascista no come...

-De manera que el fascismo actual -insinúo con una cierta cautela- es propiamente el antiguo socialismo...

-El mismo. Sólo que ahora algunos señoritos están con nosotros. (Pla, 7 de noviembre de 1922: 1$)^{11}$.

Otra crónica la dedicó Pla a explicar la importancia de un libro -Principios de política impopular, del filósofo Giuseppe Rensi- por su tremenda difusión y lectura entre los fascistas a los que había conocido. En él se hace, según el periodista, "un desesperado llamamiento a la burguesía conservadora, a los católicos no bolchevizantes, a los reformistas no republicanos, contra todo el proletariado junto, como clase y como masa, para que sean sustituidos los principios de libertad por el principio de autoridad y de aristocracia". Denunció el cronista la exaltación de la violencia por parte del fascismo, calificada como "terrorismo individualista" y "anarquismo patriótico", pero

\footnotetext{
${ }^{11}$ El texto refleja una situación mostrada por Gentile: "Decenas de miles de trabajadores de la tierra, después de la destrucción de las organizaciones socialistas, habían afluido a los sindicatos fascistas para contar con la posibilidad de trabajar" (2015: 89).
} 
consideró que era algo que estaba por fortuna "en plena liquidación" con el acceso al poder (9 de noviembre de 1922: 1).

La última pieza de Pla explica los orígenes del fascismo como una respuesta ante el auge del socialismo, una reacción que contó con el apoyo de la burguesía, que la saludó "como una liberación". Incidió el periodista en el empleo de la violencia por parte de los fascistas los dos años previos a la "marcha sobre Roma":

El escuadrismo redobla su anarquismo patriótico, y llega, a fuerza de destruir Cámaras del trabajo, Cooperativas, Ligas y Círculos socialistas, a aterrorizar a los trabajadores. La burguesía, que había apoyado desde el primer día el fascismo, intensifica su apoyo ante el éxito del movimiento, que ve cada día afluir prosélitos del bando contrario en sus filas, por haber perdido confianza en el socialismo, por la sugestión de los éxitos fascistas, por terror o miedo, por afinidad de ideas o sabe Dios con qué fines. (11 de noviembre de 1922: 5).

\subsection{La Libertad: voz del progresismo liberal antifascista}

Augusto Barcia redactó un primer artículo de opinión en el que explicó y juzgó el fascismo ya en el gobierno. Para el periodista y diputado del Partido Reformista, el origen del nuevo movimiento político se encontraba en la reacción de "todas las fuerzas socialmente conservadoras" frente al "impetuoso movimiento comunista de 1919 a 1920". Consideró que el fascismo carecía de doctrina y que su programa de acción era "borroso e indefinido". Resumió así "el credo de la novísima organización":

Engrandecimiento de la patria, constitución de un instrumento poderoso, forjado en los moldes de una disciplina sumamente rígida, para ir asaltando todos los baluartes del Estado, imposición de las aspiraciones fascistas al Gobierno y guerra sin cuartel a las democracias todas, pero de modo especial a los socialistas y a los comunistas.

Estableció Barcia similitudes entre el fascismo y el comunismo, al igual que otros articulistas, como hemos visto ${ }^{12}$ : "Como la dogmática fascista era espiritualmente, en su origen e ideación, tan arbitraria, tan opresora, tan despótica como la del comunismo, fue inevitable el choque". Terminaba el texto abriendo la posibilidad de que el fascismo no tuviese larga vida:

Si el fascismo es una fuerza sentimental, negativa, que recogió y aprovechó un momento de cobardía y buscó un pedestal en el descontento, caerá muy pronto

\footnotetext{
12 “El propio Mussolini señaló la principal semejanza entre fascismo y bolchevismo en la conquista irrevocable del poder y en la negación del liberalismo" (Gentile, 2015: 89).
} 
sin pena ni gloria, entre impotencias y decepciones, que harán pensar a muchos cómo la resolución de los terribles problemas que trae la quiebra moral de Europa no es obra del sentimiento ni labor de la violencia. (1 de noviembre de 1922: 1).

La Libertad advirtió en un suelto que acompañaba a las noticias de agencia sobre lo que acontecía en Italia que, pese a "la censura impuesta por el nuevo Gobierno" ( 2 de noviembre de 1922: 1), la situación no era tan estable como se intentaba aparentar y que los enfrentamientos entre fascistas y comunistas parecían virulentos en algunas ciudades. Otra glosa de similares características publicada un día después advirtió de que la censura del gobierno de Mussolini estaba siendo "muy severa" y que no estaba dejando "transmitir más que los despachos que le son favorables" ( 3 de noviembre de 1922: 1).

Luis de Tapia dedicó sus "coplas del día" al fascismo y, en concreto, a los enfrentamientos entre este y las fuerzas izquierdistas, equiparando en este sentido ambas ideologías. Sirva como ejemplo una de las estrofas:

Sigan, pues, las discusiones

de unos y otros camisones

mientras sostenerlas puedan

negros y rojos varones...

(iTodos estos coscorrones

acaban en que se quedan

sin camisa las naciones!) (3 de noviembre de 1922: 1).

Un artículo de Luis de Zulueta, entonces miembro del Partido Reformista, partió de la palpable crisis de la democracia liberal: "El Parlamento no está de moda; está en crisis, está en quiebra; ha perdido su crédito en la conciencia popular. [...] Así, en toda Europa, hay jóvenes que envuelven en una misma simpatía al bolchevismo y al fascismo, al ejército rojo y a las camisas negras". No obstante, rompió una lanza a favor del parlamentarismo: "No veo que se haya ensayado cosa alguna seria, susceptible de sustituir con ventaja a un mediano parlamento" ( 8 de noviembre de 1922: 1).

Por su parte, el periodista de tendencia republicana Antonio Zozaya cargó contra las clases medias por considerarlas sustento del fascismo. Tras afirmar que "el triunfo de Mussolini y de los fascistas ha sido visto con simpatía por la clase media española", explicó que desde la implantación del sufragio universal, quienes realmente 
gobernaban eran las clases medias y que el fascismo lo que buscaba era precisamente mantener esta situación mediante la violencia:

En Italia, los fascistas lo primero que han procurado ha sido disolver las Agrupaciones obreras y perseguir a sus miembros a sangre y fuego; su afán no ha sido el de procurar avance alguno, sino el de mantener el 'statu quo'.

No estaba sin embargo la opinión de Zozaya movida por la ideología marxista, sino que, desde planteamientos concordantes con el liberalismo, aseguró que todos los partidos de clase eran "esencialmente egoístas" porque "una sociedad no es una sola clase" (8 de noviembre de 1922: 1-2) ${ }^{13}$.

Gabriel Alomar, quien años después fue el embajador de la Segunda República en Italia, dedicó un artículo al fascismo en el gobierno. Fue claro en su valoración sobre la naturaleza de esta llegada al poder, de la que responsabilizó acremente a la monarquía:

Italia acaba de sufrir un golpe de Estado. Ya pueden esforzarse sus políticos dinásticos en presentar como perfectamente constitucional la solución de la reciente crisis. No. La subida al poder de los fascistas es la resultante de un acto de fuerza, de un asalto, no la expresión libre y clara de la voluntad popular.

Vio además en la victoria del fascismo "el último esfuerzo de la burguesía, hija precisamente de la Revolución, contra el nuevo irredentismo social del proletariado" (11 de noviembre de 1922: 1).

\subsection{El Socialista: desinterés hacia el triunfo del fascismo}

El órgano del PSOE publicó muy escasas alusiones a la situación italiana, únicamente algunas brevísimas noticias procedentes de agencia y tan sólo menciones tangenciales en dos artículos. En el primero, publicado antes del comienzo de la Marcha sobre Roma, se criticó duramente la división que estaba sufriendo el socialismo italiano, una fractura que beneficiaba al fascismo:

¿Cómo extrañarse que el fascismo tome arrestos y aspire a gobernar? ¿Qué en el Poder los fascistas se desacreditarán? La peor de las calamidades que pueda caer

\footnotetext{
${ }^{13}$ Gentile subraya el papel de las clases medias en la conversión del fascismo en un movimiento de masas, pero difiere de la interpretación meramente reactiva de estas frente a la amenaza de la clase obrera. El fascismo fue, en este sentido, "un maximalismo de las clases medias orientado hacia la conquista del poder" (2002: 30).
} 
sobre un pueblo es la de ser gobernado por hombres ambiciosos, incapaces, sin corazón ni solvencia moral. (Henri, 23 de octubre de 1922: 1) ${ }^{14}$.

El segundo artículo, sin firma, hablaba de la dimisión del teniente coronel Millán Astray en el contexto del conflicto entre oficiales africanistas y junteros. Un grupo de estudiantes se manifestó en apoyo del jefe de la Legión y El Socialista hizo un comentario que visibilizaba el atractivo que el fascismo italiano empezaba a despertar entre algunos jóvenes:

Estos muchachos, los más jóvenes de la clase estudiantil, han adoptado una actitud en la que vemos un poco de mimetismo en relación con el fenómeno de popularidad que rodea a los adeptos de Mussolini en la Italia fascista. (13 de noviembre de 1922: 1).

\section{A modo de conclusión}

Si bien $A B C$ no dedicó editoriales a la Marcha sobre Roma, las crónicas de su corresponsal en Italia, así como los artículos de opinión publicados al respecto, manifestaron homogéneamente entusiasmo o, cuando menos, simpatía hacia el movimiento fascista. El rechazo del diario de Luca de Tena al marxismo le hizo valorar el fascismo como una poderosa fuerza de reacción capaz de detener la revolución que, a semejanza de la bolchevique en Rusia, amenazaba otros países, entre ellos España. En relación con esto, se plasmó también una habitual justificación o atenuación de la violencia fascista, entendida como necesaria para terminar con la amenaza marxista. Además, en la mayoría de los textos analizados es evidente un rechazo sin paliativos hacia el sistema liberal parlamentario, en una lectura que se hacía también mirando hacia España. $A B C$ constituyó por todo ello una influyente tribuna desde la que se proyectó una imagen positiva del movimiento fascista esencialmente motivada por dos rasgos de este: su antimarxismo y su antiparlamentarismo.

La posición de El Debate presentó, pese a compartir postura derechista, algunas diferencias sustanciales con $A B C$. El diario dirigido por Ángel Herrera se mostró receloso ante la violencia ejercida por los fascistas y fue mostrándose más receptivo hacia estos conforme percibió moderación, motivada en su opinión por la asunción de responsabilidades de gobierno. En todo caso, el manifestado respeto del fascismo hacia la Iglesia Católica, incluida la entrada de dos ministros populares en el gobierno de Mussolini, fue la verdadera piedra de toque que demostró la aceptabilidad del PNF

\footnotetext{
${ }^{14}$ A finales de 1920, Mussolini relanzó el fascismo aprovechando precisamente que el socialismo italiano estaba "minado en su interior por las divisiones entre maximalistas, reformistas y comunistas". Estos últimos se escindieron en enero de 1921 (Gentile, 2015: 38).
} 
para El Debate. El diario católico estaba dispuesto a mostrar simpatía por el fascismo si este potenciaba su cara conservadora -mantenimiento del orden público y social, así como respeto hacia la religión católica- en detrimento de la extremista. Podría afirmarse que la actitud de El Debate fue un reflejo de la que mantuvo la propia Santa Sede.

El Sol dio cabida a posturas divergentes sobre el acceso al poder de Mussolini, desde la profascista de Maeztu hasta la nítidamente antifascista de Araquistáin. Fue, por lo tanto, el diario más heterogéneo en su valoración acerca de la Marcha sobre Roma. Editorialmente, quedó a la expectativa, confiado en que el fascismo, una vez en el poder, se adaptaría al régimen vigente y lo acataría, al igual que pensaron los dirigentes liberales italianos del momento. En relación con esto, varios artículos dejaron traslucir que el fascismo sería algo transitorio. Se criticó su violencia, pero fue habitual asimismo verlo como una reacción al extremismo de signo opuesto, también rechazable.

La Libertad no se pronunció editorialmente ni contó con corresponsal propio, pero publicó varios artículos de opinión, que coincidieron en criticar el fascismo desde la defensa de posiciones liberales progresistas y democráticas. Al igual que El Sol, valoraron negativamente la violencia escuadrista y vieron el fenómeno fascista esencialmente como una defensa frente a la posible conquista del poder por el proletariado. Se estableció además una identificación entre el fascismo y el régimen soviético, también perceptible, en menor medida, en El Sol, lo que permite entrever un anticomunismo presentado de manera indirecta. Con todo, La Libertad fue el diario que más coherentemente mostró una postura antifascista.

No deja de llamar la atención el escaso eco que despertaron en El Socialista la Marcha sobre Roma y el nuevo gobierno fascista. Si bien contaba con muchas menos páginas que el resto de los periódicos, lo que limitaba la profusión de temas, es difícil de comprender el desinterés del diario oficial del PSOE a la hora de comentar o valorar el ascenso del fascismo al poder, teniendo en cuenta que en él primaba la opinión frente a la información y que habían sido los socialistas italianos quienes más habían sufrido los embates del fascismo.

\section{Referencias hemerográficas}

ALCALÁ GALIANO, Á. (8 de noviembre de 1922): "La 'reacción' contra la anarquía", $A B C$, p. 3. 
- (14 de noviembre de 1922): "Parlamentarismo estéril y democracia anticuada", $A B C$, p. 4.

ALOMAR, G. (11 de noviembre de 1922): “La cuarta Roma”, La Libertad, p. 1.

ARAQUISTÁIN, L. (5 de noviembre de 1922): “Parlamentarismo y acción directa”, El Sol, p. 1.

BARCIA, A. (1 de noviembre de 1922): "La crisis de Europa", La Libertad, p. 1.

DAFFINA, E. O. (30 de octubre de 1922): "Mussolini, encargado del Poder", El Debate, p. 1.

- (31 de octubre de 1922): "La evolución del fascismo", El Debate, p. 3.

- (30 de octubre de 1922a): “Otro llamamiento del Papa”, El Debate, p. 1.

- (30 de octubre de 1922b): “Dice 'L'Osservatore'”, El Debate, p. 1.

- (10 de noviembre de 1922): "No habrá empréstitos extranjeros", El Debate, p. 2.

— (13 de noviembre de 1922): “Los fascistas y la Religión”, El Debate, p. 3.

DE MAEZTU, R. (7 de noviembre de 1922): “Un fascismo ideal”, El Sol, p. 1.

DE OLASCOAGA, R. (4 de noviembre de 1922): "Las elecciones inglesas", El Debate, p. 1.

DE TAPIA, L. (3 de noviembre de 1922): “Camisa negra”, La Libertad, p. 1.

DE ZULUETA, L. (8 de noviembre de 1922): “¿Nueva izquierda o vieja derecha?”, La Libertad, p. 1.

EDITORIAL (28 de octubre de 1922): “La crisis italiana”, EI Sol, p. 5.

EDITORIAL (31 de octubre de 1922): “El fascismo en el gobierno”, El Sol, p. 5.

EDITORIAL (2 de noviembre de 1922): “Una cosa es predicar...”, El Debate, p. 1.

EDITORIAL (4 de noviembre de 1922): "Hacia la derecha”, El Debate, p. 1.

“GAZIEL" (1 de noviembre de 1922): “Signos del tiempo", La Vanguardia, p. 14.

GÓMEZ DE BAQUERO, E. (4 de noviembre de 1922): "Los venenos de la guerra", El Sol, p. 5.

HENRI (23 de octubre de 1922): “Una división más”, El Socialista, p. 1.

PLA, J. (31 de octubre de 1922): "Camisas y esperanzas", El Sol, p. 5.

— (2 de noviembre de 1922): “En plena contrarrevolución”, El Sol, p. 5. 
- (4 de noviembre de 1922): "El hombre del momento: Mussolini”, El Sol, p. 1.

- (7 de noviembre de 1922): "De Florencia a Bolonia en un tren fascista", El Sol, p. 1.

- (9 de noviembre de 1922): “Un manual de la época”, El Sol, p. 1.

- (11 de noviembre de 1922): “Historia del fascismo", El Sol, p. 5.

SALAVERRÍA, J. M. (7 de noviembre de 1922): “El fascio y España”, ABC, p. 3.

- (11 de noviembre de 1922): “El caso Mussolini”, La Vanguardia, p. 10.

- (15 de noviembre de 1922): "El que influía en el siglo XX", $A B C$, p. 3.

SÁNCHEZ MAZAS, R. (3 de noviembre de 1922): “ABC en Roma. La revolución a paso gentil", $A B C$, p. 3.

- (15 de noviembre de 1922: "ABC en Italia. La victoria fascista y la marcha sobre Roma", $A B C$, p. 6.

SIN FIRMA (13 de noviembre de 1922): "Por simpatía con el Tercio huelgan unos estudiantes", El Socialista, p. 1.

SUELTO (2 de noviembre de 1922): sin título, La Libertad, p. 1.

SUELTO (3 de noviembre de 1922): sin título, La Libertad, p. 1.

ZOZAYA, A. (8 de noviembre de 1922): “Poder de las medianías”, La Libertad, pp. 1-2.

\section{Referencias bibliográficas}

ALTHEIDE, D. L. (1996): Qualitative Media Analysis, Thousand Oaks, Sage.

BARRERA, C. (2004a): "La progresiva modernización de la prensa en España", en Barrera, C. (coord.), Historia del Periodismo Universal, Barcelona, Ariel, pp. 119134.

- (2004b): "Los medios de comunicación en España”, en Barrera, C. (coord.), Historia del Periodismo Universal, Barcelona, Ariel, pp. 285-318.

DESVOIS, J. M. (1977): La prensa en España (1900-1931), Madrid, Siglo XXI de España Editores.

- (2010): "El diario El Sol, paladín de la modernización de España (1917-1936)", en Berceo. Revista riojana de Ciencias Sociales y Humanidades, no 159, pp. 165181. 
FERGUSON, N. (2007): La guerra del mundo. Los conflictos del siglo XX y el declive de Occidente (1904-1953), Barcelona, Debate.

GENTILE, E. (2002): Fascismo. Historia e interpretación, Madrid, Alianza Editorial. - (2015): El fascismo y la marcha sobre Roma. El nacimiento de un régimen, Barcelona, Edhasa.

GRIFFIN, R. (2010): Modernismo y fascismo. La sensación de comienzo bajo Mussolini y Hitler, Madrid, Akal.

GUASCH BORRAT, J. M. (1986): El Debate y la crisis de la Restauración, Pamplona, Eunsa.

GUTIÉRREZ, J. E. (2010): “Catolicismo y fascismo en la prensa católica hispanoamericana durante las entreguerras: Venezuela y España", en Procesos históricos, no 17, pp. 19-32.

HERNÁNDEZ SANDOICA, H. (1992): Los fascismos europeos, Madrid, Ediciones Istmo.

MAINER, J. C. (2013): Falange y literatura, Barcelona, RBA.

MAUREL, M. (2005): “Un asunto de FE: fascismo en España (1933-1936)”, en Gallego, F., y Morente, F. (eds.), Fascismo en España, Barcelona, El Viejo Topo, pp. 133162.

MORAL SANDOVAL, E. (1987): “El Socialista (1913-1936)”, en VV.AA., Prensa obrera en Madrid (1855-1936), Madrid, Alfoz, pp. 519-546.

PAYNE, S. G. (1995): Historia del fascismo, Barcelona, Planeta.

PELOILLE, M. (2003): “Seducidos y expectantes: los liberales españoles ante el primer fascismo italiano", en España contemporánea: revista de literatura y cultura, tomo 16, no 2, pp. 71-94.

- (2004): "Barcelona, Madrid, Roma. Miradas cruzadas sobre fascismo", en Ludec, N., y Dubosquet Lairys, F. (coords,), Centros y periferias. Prensa, impresos y territorios en el mundo hispánico contemporáneo, Burdeos, Université Michel de Montaigne, pp. 179-189.

- (2005): Fascismo en ciernes. España 1922-1930. Textos recuperados, Toulouse, Presses Universitaires du Mirail.

- (2009): “Recensement des articles d'opinion sur l'Italia fasciste, dans les quotidiens espagnols: $A B C$, El Debate, La Época. Heraldo de Madrid, La Libertad et El Sol, du 25 octobre 1922 au 28 février 1929", en Cahiers de civilisation espagnole contemporaine, $\mathrm{n}$ ㅇ 5. Disponible en Internet (9-10-2019): http://journals.openedition.org/ccec/3168 
PELLEGRINI, A. (2009): La Italia fascista en la prensa española (1940-1945), tesis doctoral, Universitat de Barcelona, 2009.

PRESTON, P. (1986): Las derechas españolas en el siglo XX: autoritarismo, fascismo y golpismo, Madrid, Sistema.

RODRÍGUEZ JIMÉNEZ, J. L. (1997): La extrema derecha española en el siglo XX, Madrid, Alianza.

RUIZ CARNICER, M. A. (2015): "La modernidad retorcida: raíces y origen de la cultura política fascista", en Forcadell, C., y Suárez Cortina, M. (coords.), La Restauración y la República (1874-1936), Zaragoza, Marcial Pons-Prensas de la Universidad de Zaragoza, pp. 345-376.

SÁNCHEZ ARANDA, J. J., y BARRERA, C. (1992): Historia del periodismo español. Desde sus orígenes hasta 1975, Pamplona, Eunsa.

SEOANE, M. C., y SÁIZ, M. D. (1996): Historia del periodismo en España 3. El siglo XX: 1898-1936, Madrid, Alianza.

- (2007): Cuatro siglos de periodismo en España. De los avisos a los periódicos digitales, Madrid, Alianza. 